EESTI NSV TEADUSTE AKADEEMIA TOIMETISED. 20. KOIDE

KEEMIA * GEOLOOGIA. 1971, NR. 2

ИЗВЕСТИЯ АКАДЕМИИ НАУК ЭСТОНСКОЙ ССР. ТОМ 20

ХИМИЯ * ГЕОЛОГИЯ. 1971, Nㅗ 2

удК $541.571 .9: 547.561$

А. ААРНА, Л. МЭЛДЕР, АИМЕ СУУРПЕРЕ

\title{
ИССЛЕДОВАНИЕ АССОЦИАЦИИ ФЕНОЛОВ В НЕПОЛЯРНЫХ РАСТВОРИТЕЛЯХ
}

\section{СООБЩЕНИЕ II}

В первом сообщении [ $\left.{ }^{1}\right]$ были приведены формулы для расчета констант ассоциации из экспериментальных данных, полученных в виде зависимости между общей (стехиометрической) концентрацией $(Q)$ и фактической концентрацией $(N)$ ассоциирующего вещества, при следующих схемах ассоциации: 1) образование только одного -ассоциата определенного состава; 2) цегочечная ассоциация при постоянстве константы равновесия для реакции присоединения мономера к цепи; 3) цепочечная ассоциация при непостоянстве константы равновесия для реакции присоединения мономера к пепи. В настоящей работе приводятся результаты определения констант ассоциации и термодинамических характеристик для фенола и изомерных метилфенолов в разных неполярных растворителях по данным эбуллиоскопических измерений.

\section{Экспериментальная часть}

Подготовка веществ. Примеси нейтрального и основного характера удалялись из фенолов (ч.) путем дистилляции с водяным паром в щелочной среде. 4-Метилфенол очищался от 3-метилфенола обработкой концентрированной серной кислотой. После этого все фенолы ректифицировались в лабораторной колонке с 70 ТТ. Циклогексан и $H$-гексан обрабатывались сплавом $\mathrm{NaK}(1: 1)$ при температуре кипения растворителя по методике $\left[{ }^{2}\right]$ и ректифицировались в колонке с 70 TT. $н$-Гептан обрабатывался дважды $20 \%$-ным олеумом, затем моногидратом серной кислоты, промывался водой и разбавленным раствором КОН и ректифицировался над натрием.

Чистота очищенных веществ проверялась методом газовой хроматографни на хроматографе «Цвет» с пламенно-ионизационным детектором и по температуре плавления фенолов. При хроматографическом анализе в качестве стационарной фазы для фенолов и углеводородов нормального строения использовался апиезон $L(15 \%)$ на хромосорбе $W$, для циклогексана - твин $80(15 \%)$ на хромосорбе $W$.

Методика опытов. Для измерения повышения температуры кипения растворителя при растворении в нем фенолов использовался эбуллиометр типа насоса Котрелла, видоизмененный В. Михкельсоном [3]. Во избежание попадания влаги в растворитель вся система была изолирована от атмосферы хлоркальциевыми трубками. Температура жидкой фазы измерялась с помощью чувствительного термометра сопротивления по методике, описанной в работе [3]. Использованный термометр 
имел следующие показатели: сопротивление при $56^{\circ} \mathrm{C}-93,37 \kappa \Omega$, при $100^{\circ}-22,45 \kappa \Omega$, температурный коэффициент сопротивления при $56^{\circ}$ - 3,482 \%/град, при $100^{\circ}$ - 3,010\%/град, что соответствует чувствительности при $56^{\circ}-3,00 \cdot 10^{-4}$ град/ $\Omega$ и при $100^{\circ}$.

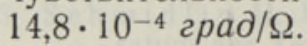

В каждом опыте количество растворителя в эбуллиометре поддерживалось строго постоянным $(15$ мл). Концентрация растворенного вещества в отдельных сериях изменялась путем последовательного введения $10-12$ навесок в пределах $0,05-0,60$ моль/ $\Omega$, чему соответствует повышение температуры кипения раствора в среднем на $0,25-1,5^{\circ}$ (повышение температуры кипения раствора при максимальной концентрации в зависимости от протяжения ассоциации при разных парах фенол-растворитель изменялось в пределах $\left.1,1-2,0^{\circ}\right)$. Однако небольшая часть растворителя во время измерений находится в парообразном состоянии, вследствие чего фактическая концентрация растворенного вєщества в жидкой фазе является несколько выше расчетной. Так как количество парообразного раствсрителя в приборе не превышает $0,3 \%$ и для данного растворителя при заданном давлении является постоянным, соответствующая поправка для концентрации не вводилась. Указанная ошибка при определении концентрации фенола в жидкой фазе вносит также некоторую систематическую ошибку (в сторону уменьшения) в константу равновесия.

В каждом растворителе опыты проводились при двух давлениях при атмосферном и при $8,0 \cdot 10^{4} \mathrm{H} / \mathrm{M}^{2}$ (600 мм рт. ст.). Постоянство давления в системе поддерживалось при помощи электромагнитного маностата. В течение одной серии опытов колебания давления не превышали 0,025 мм рт. ст., чему соответствует изменение температуры кипения раствора в среднем на $0,001^{\circ}$.

Постоянная температура кипения жидкости в эбуллиометре устанавливалась, как правило, через 3 мин после введения навески вещества. Пссле этого наблюдались только случайные колебания показаний нулевого гальванометра, вызываемые главным образом флюктуациями жидкостного потока на термометре, а также нестабильностью электрической системы измерения, колебаниями напряжения в системе нагрева жидкости и в системе регулирования давления. Температура кипения жидкости измерялась как средняя из 13 отсчетов (через каждые 15 сек) в вакууме и 5 отсчетов при атмосферном давленин. Как правило, стандартное отклонение (средняя квадратическая ошибка) отсчета температуры не превышало $0,5 \%$ от измеренной разности температур, что с достоверностью $95 \%$ дает точность измеренной разности температур $\pm 0,31 \%$.

Обработка экспериментальных данных. Результаты эбуллиоскопических измерений использовались для непосредственного определения фактора ассоциации растворенного вещества $(f)$ при данной конщентрации, который рассчитывался как соотношение фактического $(M)$ и стехиометрического $\left(M_{0}\right)$ молекулярных весов:

$$
\tilde{f}=\frac{Q}{N}=\frac{M}{M_{0}}=\frac{\left(\frac{d t}{d q}\right)_{0}}{\frac{\Delta t}{q}}
$$

где

$$
\left(\frac{d t}{d q}\right)_{0}=\lim _{q \rightarrow 0} \frac{\Delta i}{q}=\frac{1000 K_{3}}{M_{0} W}
$$


$\Delta t$ - повышение температуры кипения $W_{2}(15,0$ м. $)$ растворителя с эбуллиоскопической постоянной $K_{\text {э }}$ при растворении в нем $q$ г вещества.

Для каждого растворителя, использованного в настоящей работе, эбуллиоскопическая постоянная $K_{\ni}$ при данной температуре была определіена непосредственно из опытных данных путем экстраполяции зависимости $\Delta t i q$ от $q$ (или $Q$ ) до нулевой концентрации. Для любой использованной пары веществ при постоянном количестве растворителя указанная зависимость хорошо подчиняется эмпирическому уравнению

$$
\frac{\Delta t}{q}=a Q^{2}+b Q+c
$$

откуда

$$
\left(\frac{d t}{d q}\right)_{0}=\frac{1000 K_{3}}{M_{0} W}=c
$$

определено на ЭВМ методом наименьших квадратов.

Опыты показали, что для одноатомных фенолов в неполярных растворителях зависимость фактора ассоциации $f$ от стехиометрической концентрации $Q$ явно не подчиняется схемам ассоциации с предположением образования только одного ассоциата определенного состава, но хорошо описывается уравнением:

$$
\frac{f(j-1)}{Q}=\alpha f+\beta
$$

полученным из уравнения (15) в [1]. Для расчета эмпирических числовых коэффициентов $\alpha$ и $\beta$ непосредственно из измеренных величин

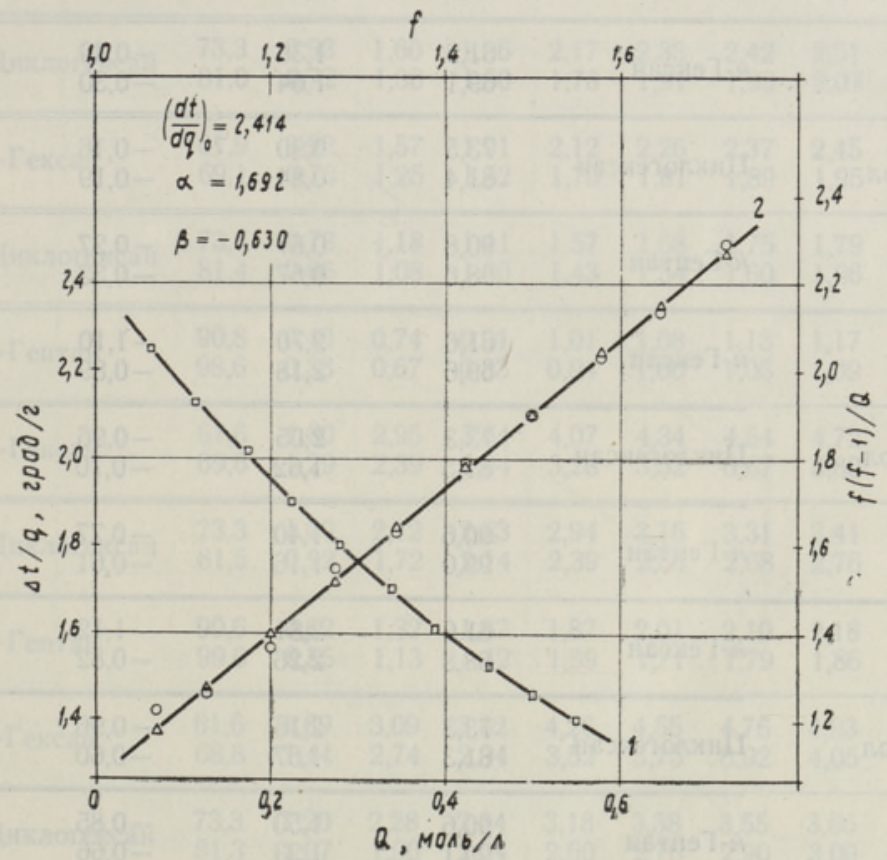

Рис. 1. Определение $(d t / d q), \alpha$ и $\beta$ для 4 -метилфенола в циклогексане при температуре $81,3^{\circ} \mathrm{C}$.

$I-$ зависимость $\Delta t / q$ от $Q, 2-$ зависимость $f(f-1) / Q$ от $f$;

$\square-$ экспериментальные точки $\Delta t / q$ при различных $Q$. $0-f$ вычислен

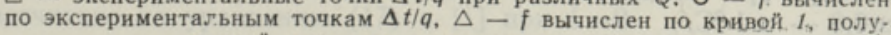
ченной методом наименьших квадратов. 
Таблица 1

Значения $\Delta t i q$ и $f$ при различных $Q$ для 4-метилфенола в циклогексане при $81,3{ }^{\circ} \mathrm{C}$

\begin{tabular}{c|c|c|c|c}
\hline \multirow{2}{*}{$\begin{array}{c}Q \\
\text { моль } / \Omega\end{array}$} & \multicolumn{2}{|c|}{$\Delta t / q$, град/с } & \multicolumn{2}{|c}{$f$} \\
\cline { 2 - 3 } \cline { 5 - 5 } & измерено & вычислено & измерено & вычислено \\
\hline \multirow{2}{*}{0,063} & 2,252 & 2,257 & 1,072 & \\
0,166 & 2,136 & 2,135 & 1,130 & 1,070 \\
0,173 & 2,016 & 2,008 & 1,197 & 1,131 \\
0,226 & 1,894 & 1,900 & 1,274 & 1,202 \\
0,280 & 1,800 & 1,797 & 1,341 & 1,344 \\
0,339 & 1,689 & 1,694 & 1,429 & 1,425 \\
0,391 & 1,610 & 1,610 & 1,499 & 1,499 \\
0,448 & 1,530 & 1,527 & 1,578 & 1,581 \\
0,494 & 1,468 & 1,466 & 1,644 & 1,646 \\
0,548 & 1,399 & 1,401 & 1,726 & 1,724
\end{tabular}

Таблица 2

Параметры $\alpha, \beta$ и константы димеризации фенолов в углеводородных растворителях

\begin{tabular}{|c|c|c|c|c|c|}
\hline Фенол & Растворитель & $\begin{array}{l}\text { Темпера- } \\
\text { тура, }{ }^{\circ}{ }^{\circ} \mathrm{C}\end{array}$ & $\alpha$ & $\beta$ & $K_{12}, \Omega /$ моль \\
\hline \multirow[t]{2}{*}{ Фенол } & $н$-Гексан & $\begin{array}{l}61,7 \\
68,9\end{array}$ & $\begin{array}{l}2,01 \\
1,93\end{array}$ & $\begin{array}{l}-0,68 \\
-0,86\end{array}$ & $\begin{array}{l}1,33 \\
1,07\end{array}$ \\
\hline & Циклогексан & $\begin{array}{l}73,3 \\
81,0\end{array}$ & $\begin{array}{l}1,35 \\
1,16\end{array}$ & $\begin{array}{l}-0,42 \\
-0,43\end{array}$ & $\begin{array}{l}0,93 \\
0,72\end{array}$ \\
\hline \multirow{3}{*}{ 2-Метилфенол } & н-Гексан & $\begin{array}{l}61,9 \\
69,1\end{array}$ & $\begin{array}{l}1,30 \\
1,04\end{array}$ & $\begin{array}{l}-0,39 \\
-0,30\end{array}$ & $\begin{array}{l}0,92 \\
0,73\end{array}$ \\
\hline & Циклогексан & $\begin{array}{l}73,5 \\
81,4\end{array}$ & $\begin{array}{l}0,90 \\
0,84\end{array}$ & $\begin{array}{l}-0,16 \\
-0,19\end{array}$ & $\begin{array}{l}0,73 \\
0,66\end{array}$ \\
\hline & $\boldsymbol{\mu}$-Гептан & $\begin{array}{l}90,8 \\
98,6\end{array}$ & $\begin{array}{l}0,67 \\
0,67\end{array}$ & $\begin{array}{l}-0,27 \\
-0,33\end{array}$ & $\begin{array}{l}0,40 \\
0,34\end{array}$ \\
\hline \multirow{3}{*}{ 3-Метилфенол } & $\boldsymbol{H}$-Гексан & $\begin{array}{l}61,6 \\
69,6\end{array}$ & $\begin{array}{l}2,70 \\
2,18\end{array}$ & $\begin{array}{l}-1,10 \\
-0,89\end{array}$ & $\begin{array}{l}1,60 \\
1,29\end{array}$ \\
\hline & Циклогексан & $\begin{array}{l}73,3 \\
81,5\end{array}$ & $\begin{array}{l}2,05 \\
1,62\end{array}$ & $\begin{array}{l}-0,96 \\
-0,70\end{array}$ & $\begin{array}{l}1,09 \\
0,92\end{array}$ \\
\hline & $н$-Гептан & $\begin{array}{l}90,6 \\
99,0\end{array}$ & $\begin{array}{l}1,40 \\
1,16\end{array}$ & $\begin{array}{l}-0,77 \\
-0,61\end{array}$ & $\begin{array}{l}0,62 \\
0,55\end{array}$ \\
\hline \multirow{3}{*}{ 4-Метилфенол } & н-Гексан & $\begin{array}{l}61,6 \\
68,8\end{array}$ & $\begin{array}{l}2,81 \\
2,26\end{array}$ & $\begin{array}{l}-1,12 \\
-0,82\end{array}$ & $\begin{array}{l}1,69 \\
1,44\end{array}$ \\
\hline & Циклогексан & $\begin{array}{l}73,3 \\
81,3\end{array}$ & $\begin{array}{l}2,16 \\
1,67\end{array}$ & $\begin{array}{l}-0,96 \\
-0,60\end{array}$ & $\begin{array}{l}1,20 \\
1,07\end{array}$ \\
\hline & $н$-Гептан & $\begin{array}{l}90,6 \\
99,1\end{array}$ & $\begin{array}{l}1,50 \\
1,23\end{array}$ & $\begin{array}{l}-0,85 \\
-0,66\end{array}$ & $\begin{array}{l}0,65 \\
0,57\end{array}$ \\
\hline
\end{tabular}

* Средняя температура опытов, проведенных с данной парой веществ при данном давлении. Температура жидкости в отдельных опытах отличается от средней максимально на $\pm 0,6- \pm 1^{\circ} \mathrm{C}$. 
$\Delta t$; составлялась специальная программа для ЭВМ. Так как измеренные и рассчитанные по формуле (2) значения $\Delta t / q$ отличались несущественно (табл. 1), то при вычислении $f$ использовались рассчитанные величины $\Delta t / q$, полученные методом наименьших квадратов из опытных данных. На рис. 1 в качестве примера приводятся зависимости $\Delta t / q$ от $Q$ и $f(f-1) / Q$ от $f$ для 4-метилфенола в циклогексане, которые показывают, что расхождение величин $f(f-1) / Q$, рассчитанных непосредственно из опытных данных и найденных из расчетных значений $\Delta t / Q$, незначительно и не имеет систематического характера.

\section{Закономерности ассоциации фенолов}

В табл. 2 приводятся значения $\alpha, \beta$ и $K_{12} *$ для изученных систем. Приведенные $\alpha$ и $\beta$ получены как арифметические средние нескольких серий опытов при данной температуре. Как правило, расхождение констант димеризации, рассчитанных нз $\alpha$ и $\beta$ разных серий опытов, не превышает $\pm 5 \%$ (в большинстве случаев 2-3\%).

Для всех изученных систем при любой температуре $\alpha>0$, что соот-

Таблица :

Константы ассоциации $K_{(L-1) L}$ фенолов в углеводородных растворителях, $\Omega /$ моль

\begin{tabular}{|c|c|c|c|c|c|c|c|c|c|c|c|}
\hline Фенол & $\begin{array}{c}\text { Раствори- } \\
\text { тель }\end{array}$ & $\begin{array}{l}\text { Tем- } \\
\text { пера- } \\
\text { тура. } \\
{ }^{\circ} \mathrm{C}\end{array}$ & $K_{12}$ & $K_{23}$ & $K_{34}$ & $K_{45}$ & $K_{56}$ & $K_{67}$ & $K_{78}$ & $K_{89}$ & $K_{910}$ \\
\hline \multirow{2}{*}{ Фенол } & н-Гексан & $\begin{array}{l}61,7 \\
68,9\end{array}$ & $\begin{array}{l}1,33 \\
1,07\end{array}$ & $\begin{array}{l}2,33 \\
2,04\end{array}$ & $\begin{array}{l}2,86 \\
2,52\end{array}$ & $\begin{array}{l}3,18 \\
2,82\end{array}$ & $\begin{array}{l}3,40 \\
3,01\end{array}$ & $\begin{array}{l}3,55 \\
3,17\end{array}$ & $\begin{array}{l}3,66 \\
3,26\end{array}$ & $\begin{array}{l}3,77 \\
3,36\end{array}$ & $\begin{array}{l}3,83 \\
3,41\end{array}$ \\
\hline & Циклогексан & $\begin{array}{l}73,3 \\
81,0\end{array}$ & $\begin{array}{r}0,93 \\
-0,72\end{array}$ & $\begin{array}{l}1,60 \\
1,30\end{array}$ & $\begin{array}{l}1,96 \\
1,60\end{array}$ & $\begin{array}{l}2,17 \\
1,78\end{array}$ & $\begin{array}{l}2,33 \\
1,91\end{array}$ & $\begin{array}{l}2,42 \\
1,99\end{array}$ & $\begin{array}{l}2,51 \\
2,07\end{array}$ & $\begin{array}{l}2,57 \\
2,11\end{array}$ & $\begin{array}{l}2,62 \\
2,15\end{array}$ \\
\hline \multirow{3}{*}{$\begin{array}{l}\text { 2-Метил- } \\
\text { фенол }\end{array}$} & н-Гексан & $\begin{array}{l}61,9 \\
69,1\end{array}$ & $\begin{array}{l}0,92 \\
0,73\end{array}$ & $\begin{array}{l}1,57 \\
1,25\end{array}$ & $\begin{array}{l}1,91 \\
1,52\end{array}$ & $\begin{array}{l}2,12 \\
1,70\end{array}$ & $\begin{array}{l}2,26 \\
1,81\end{array}$ & $\begin{array}{l}2,37 \\
1,89\end{array}$ & $\begin{array}{l}2,45 \\
1,95\end{array}$ & $\begin{array}{l}2,50 \\
2,01\end{array}$ & $\begin{array}{l}2,56 \\
2,03\end{array}$ \\
\hline & Циклогексан & $\begin{array}{l}73,5 \\
81,4\end{array}$ & $\begin{array}{l}0,73 \\
0,66\end{array}$ & $\begin{array}{l}1,18 \\
1,08\end{array}$ & $\begin{array}{l}1,41 \\
1,30\end{array}$ & $\begin{array}{l}1,57 \\
1,43\end{array}$ & $\begin{array}{l}1,68 \\
1,54\end{array}$ & $\begin{array}{l}1,75 \\
1,60\end{array}$ & $\begin{array}{l}1,79 \\
1,66\end{array}$ & $\begin{array}{l}1,85 \\
1,69\end{array}$ & $\begin{array}{l}1,89 \\
1,73\end{array}$ \\
\hline & $\boldsymbol{H}$-Гептан & $\begin{array}{l}90,8 \\
98,6\end{array}$ & $\begin{array}{l}0,40 \\
0,33\end{array}$ & $\begin{array}{l}0,74 \\
0,67\end{array}$ & $\begin{array}{l}0,91 \\
0,83\end{array}$ & $\begin{array}{l}1,01 \\
0,94\end{array}$ & $\begin{array}{l}1,08 \\
1,00\end{array}$ & $\begin{array}{l}1,13 \\
1,05\end{array}$ & $\begin{array}{l}1,17 \\
1,09\end{array}$ & $\begin{array}{l}1,19 \\
1,11\end{array}$ & $\begin{array}{l}1,22 \\
1,14\end{array}$ \\
\hline \multirow{3}{*}{$\begin{array}{l}\text { 3-Метил- } \\
\text { фенол }\end{array}$} & н-Гексан & $\begin{array}{l}61,6 \\
69,6\end{array}$ & $\begin{array}{l}1,60 \\
1,29\end{array}$ & $\begin{array}{l}2,95 \\
2,39\end{array}$ & $\begin{array}{l}3,64 \\
2,94\end{array}$ & $\begin{array}{l}4,07 \\
3,28\end{array}$ & $\begin{array}{l}4,34 \\
3,52\end{array}$ & $\begin{array}{l}4,54 \\
3,67\end{array}$ & $\begin{array}{l}4,72 \\
3,80\end{array}$ & $\begin{array}{l}4,83 \\
3,90\end{array}$ & $\begin{array}{l}5,49 \\
4,35\end{array}$ \\
\hline & Циклогексап & $\begin{array}{l}73,3 \\
81,5\end{array}$ & $\begin{array}{l}1,09 \\
0,92\end{array}$ & $\begin{array}{l}2,12 \\
1,72\end{array}$ & $\begin{array}{l}2,63 \\
2,14\end{array}$ & $\begin{array}{l}2,94 \\
2,39\end{array}$ & $\begin{array}{l}3,16 \\
2,56\end{array}$ & $\begin{array}{l}3,31 \\
2,68\end{array}$ & $\begin{array}{l}3,41 \\
2,76\end{array}$ & $\begin{array}{l}3,50 \\
2,84\end{array}$ & $\begin{array}{l}3,58 \\
2,90\end{array}$ \\
\hline & н-Гептан & $\begin{array}{l}90,6 \\
99,0\end{array}$ & $\begin{array}{l}0,62 \\
0,55\end{array}$ & $\begin{array}{l}1,32 \\
1,13\end{array}$ & $\begin{array}{l}1,67 \\
1,42\end{array}$ & $\begin{array}{l}1,87 \\
1,59\end{array}$ & $\begin{array}{l}2,01 \\
1,71\end{array}$ & $\begin{array}{l}2,10 \\
1,79\end{array}$ & $\begin{array}{l}2,18 \\
1,86\end{array}$ & $\begin{array}{l}2,23 \\
1,90\end{array}$ & $\begin{array}{l}2,28 \\
1,94\end{array}$ \\
\hline \multirow{3}{*}{$\begin{array}{l}\text { 4-Метил- } \\
\text { фенол }\end{array}$} & н-Гексан & $\begin{array}{l}61,6 \\
68,8\end{array}$ & $\begin{array}{l}1,69 \\
1,44\end{array}$ & $\begin{array}{l}3,09 \\
2,74\end{array}$ & $\begin{array}{l}3,82 \\
2,94\end{array}$ & $\begin{array}{l}4,26 \\
3,52\end{array}$ & $\begin{array}{l}4,55 \\
3,75\end{array}$ & $\begin{array}{l}4,76 \\
3,92\end{array}$ & $\begin{array}{l}4,93 \\
4,05\end{array}$ & $\begin{array}{l}5,05 \\
4,17\end{array}$ & $\begin{array}{l}5,12 \\
4,23\end{array}$ \\
\hline & Циклогексан & $\begin{array}{l}73,3 \\
81,3\end{array}$ & $\begin{array}{l}1,20 \\
1,07\end{array}$ & $\begin{array}{l}2,28 \\
1,90\end{array}$ & $\begin{array}{l}2,84 \\
2,34\end{array}$ & $\begin{array}{l}3,18 \\
2,60\end{array}$ & $\begin{array}{l}3,38 \\
2,76\end{array}$ & $\begin{array}{l}3,55 \\
2,90\end{array}$ & $\begin{array}{l}3,66 \\
3,00\end{array}$ & $\begin{array}{l}3,77 \\
3,08\end{array}$ & $\begin{array}{l}3,83 \\
3,10\end{array}$ \\
\hline & H-Гептан & $\begin{array}{l}90,6 \\
99,1\end{array}$ & $\begin{array}{l}0,65 \\
0,57\end{array}$ & $\begin{array}{l}1,40 \\
1,18\end{array}$ & $\begin{array}{l}1,76 \\
1,48\end{array}$ & $\begin{array}{l}1,98 \\
1,68\end{array}$ & $\begin{array}{r}2,13 \\
1,78\end{array}$ & $\begin{array}{l}2,24 \\
1,87\end{array}$ & $\begin{array}{l}2,30 \\
1,93\end{array}$ & $\begin{array}{l}2,39 \\
2,00\end{array}$ & $\begin{array}{l}2,41 \\
2,03\end{array}$ \\
\hline
\end{tabular}

* $K_{12}$ рассчитано по уравненню (17) в [1] при $L=2$.

2 ENSV TA Toimetised K*G-2 1971 
ветствует цепочечной ассоциации, при которой мономер предпочтительно присоединяется к высшим «полимерам» [']. Рассчитанные значения для константы равновесия реакции прйсоединения мономера к цепи (табл. 3) действительно показывают, что в любом случае

$$
K_{12}<K_{23}<K_{34}<\ldots<K_{(L-1) L}<\ldots .
$$

Увеличение значений $K_{(L-1) L}$ с повышением $L$ происходит монотонно с убывающей скоростью, т. е. с повышением $L$ константа равновесия для реакции присоединения мономера к цепи приближается к определенному конечному значению.

Большинство данных, опубликованных ранее об ассоциации фенолов, получено методами ИК-спектроскопии и криоскопии в $\mathrm{CCl}_{4}$ и бензоле при сравнительно низкой температуре. По данным некоторых сравнительно поздних работ [4-6], указанные растворители, широко распространенные для подобных измерений, в действительности не являются аб́солютно индифферентными по отношению к растворенному веществу, а обусловливают уменьшение склонности последнего к ассоциации. Поэтому абсолютные величины констант ассоциации фенолов в предельных углеводородах, найденные в настоящей работе, не сравнимы с опубликованными в литературе данными. Однако сравнительная склонностьотдельных фенолов к ассоциации (2-метилфенол<фенол<3-метилфенол <4-метилфенол), обнаруженная в настоящей работе, полностью согласуется с данными, имеющимися ранее [7,8].

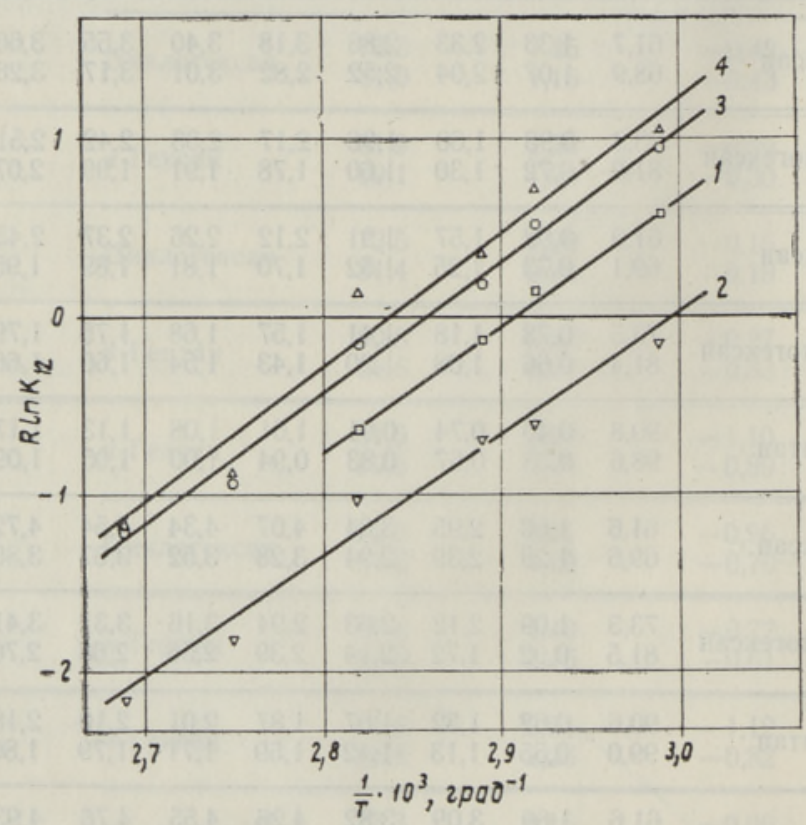

Рис. 2. Температурная зависимость констант димеризации фенола и метилфенолов.

1 (口) - фенол, 2 ( $\nabla)$ - 2-метилфенол, 3 (O) - 3-метилфенол, $4(\Delta)-4$-метилфенол.

Зависимость $R \ln K_{(L-1) L}$ от $1 / \mathrm{T}$, полученная путем измерения в трех растворителях (в каждом при двух давлениях), удовлетворяет условию линейности (рис. 2 и 3). Это показывает, что возмущающее действие дан- 
ных растворителей на процесс ассоциации фенолов является несущественным или, в крайнем случае, во всех использованных растворителях приблизительно одинаковым. Следовательно, температурную зависимость $\ln K$ можно исгользовать для расчета энтальпии водородной связи. Рассчитанные значения $-\Delta \mathrm{H}$ для реакции димеризации (табл. 4) несколько выше, чем большинство данных, приведенных в монографии Дж. Пиментела и О. МакКлеллана [9] для связей $\mathrm{O}-\mathrm{H} \ldots \mathrm{O}$ в $\mathrm{CCl}_{4}$ и бензоле, но находятся на площади гистограммы возможных значений для $-\Delta \mathrm{H}$. Очевидно, отсутствие возмущающего действия растворителя в насыщенных углеводородах

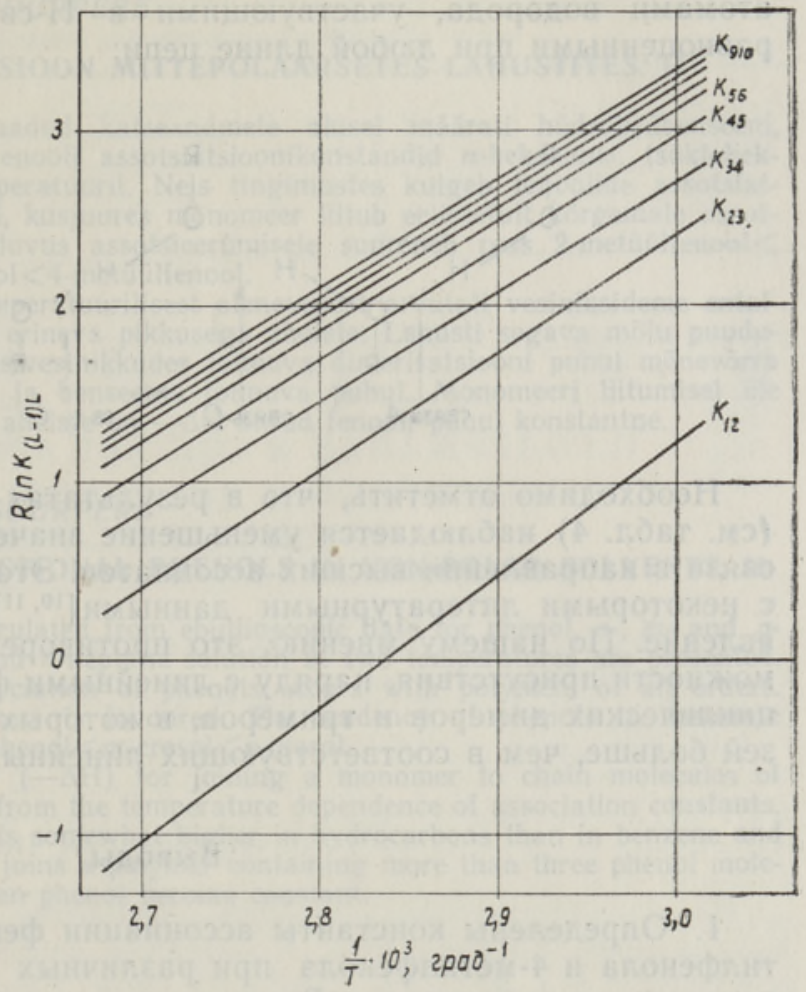

Рис. 3. Температурная зависимость константы равновесия для реакции присоединения мономера к цепи при ассоциации 4-метилфенола в углеводородных растворителях.

Таблица 4

Энтальпия водородной связи $(-\Delta \mathrm{H})$ при присоединении мономера фенола к цепочечному ассоциату $A_{L-1}$ разной длины, ккал/моль $H$-связь

\begin{tabular}{l|c|c|c|c|c|c|c|c|c}
\hline \multirow{2}{*}{ Фенол } & \multicolumn{7}{|c}{ Число молекул мономера в ассоциате $(L)$} \\
\cline { 2 - 9 } & 2 & 3 & 4 & 5 & 6 & 7 & 8 & 9 & 10 \\
\hline \multirow{2}{*}{ Фенол } & 7,4 & 7,4 & 7,4 & 7,4 & 7,4 & 7,4 & 7,3 & 7,4 & 7,4 \\
2-Метилфенол & 6,8 & 5,8 & 5,6 & 5,6 & 5,5 & 5,5 & 5,5 & 5,5 & 5,5 \\
4-Метилфенол & 7,3 & 6,5 & 6,3 & 6,3 & 6,3 & 6,3 & 6,3 & 6,3 & 6,2 \\
& 7,6 & 6,7 & 6,2 & 6,3 & 6,3 & 6,3 & 6,3 & 6,2 & 6,3
\end{tabular}

обусловливает несколько повышенные значения энтальпии водородной связи по сравнению с растворами в $\mathrm{CCl}_{4}$ и бензоле. На наличие зависимости между $-\Delta \mathrm{H}$ и $-\Delta \mathrm{S}$ (а следовательно, и между $-\Delta \mathrm{H}$ и $K$ ) для связи О-Н... О указывается также в монографии [].

Для реакции присоединения мономера к высшим «полимерам» $-\Delta \mathrm{H}$ имеет значения, которые в пределах точности определения согласуются с опубликованными в литературе. Как правило $-\Delta \mathrm{H}_{(L-1) L}$ для данного вещества является постоянной при наличии в ассоциате более трех исходных молекул. Это, очевидно, свидетельствует о том, что в полимере все водородные мостики, в которых атом кислорода соединен с двумя 
атомами водорода, участвующими в Н-связи (связи $C$ ), являются равноценными при любой длине цепи:

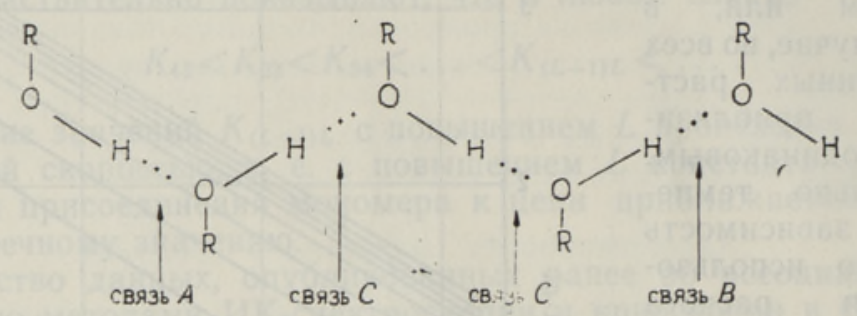

Необходимо отметить, что в результатах настоящего исследования (см. табл. 4) наблюдается уменьшение значения энтальпии водородной связи в направлении высших ассоциатов. Этот результат не согласуется с некоторыми литературными данными $\left[{ }^{10,11}\right]$, где отмечают обратное яьление. По нашему мнению, это противоречие свидетельствует о возможности присутствия, наряду с линейными формами ассоциатов, также циклических димеров и тримеров, в которых фактическое число Н-связей больше, чем в соответствующих линейных молекулярных агрегатах.

\section{Выводы}

1. Определены константы ассоциации фенола, 2-метилфенола, 3-метилфенола и 4-метилфенола при различных температурах в $H$-гексане, циклогексане и $H$-гептане. В указанных растворителях ассоциация фенолов протекает по цепочечной схеме при непостоянстве константы равновесия для реакции присоединения мономера к цепи. Мономер предпочтительно присоединяется к высшим «нолимерам».

2. Сравнительная склонность фенолов к ассоциации увеличивается в ряду: 2 -метилфенол < фенол < 3-метилфенол < 4-метилфенол.

3. Из температурной зависиміоси констант ассоциации рассчитана энтальпия водородной связи $(-\Delta \mathrm{H})$ для реакции присоединения мономера к цепочечному ассоциату различной длины. Вследствие отсутствия возмущающего влияния растворителя значение - $\Delta$ Н для реакции димеризации в углеводородах несколько выше, чем в $\mathrm{CCl}_{4}$ и бензоле. При наличии в ассоциате более трех исходных молекул фенола $-\Delta \mathrm{H}$ для данного вещества является постоянной.

\section{Л И ТЕРА Т У РА}

1. Мэлдер Л. И., С у урп е ре А. О., Изв. АН ЭССР, Хим. Геол., 20, № 1, 14 (1971).

2. Wright O. L., Va n cheri F. J., Industr. Engng Chem., 53, 15 (1961).

3. Михкельсон В. Я., Тр. Таллинск. политехн. ин-та, Сер. А, № 210, 267 (1964).

4. Fletcher A. N., Heller C. A., J. Phys. Chem., 71, 3742 (1967).

5. Cle r ba ux T., Luiz a r F. O., Bol. Soc. quím. Perú, 33, 151 (1967), C. A., 69, No. 19, $70665 u$.

6. Wolff H., Wurtz R., Ber. Bunsenges. Phys. Chem., 72, 101 (1968).

7. Mag uir e M. M., We st R., Spectrochim. Acta, 17, 369 (1961).

8. Raczy L., Constant E., Leburn A., J. chim. phys., 64, 1180 (1967).

9. Пи ментел Дж., Мак-Клеллан О., Водородная связь, М., 1964.

10. B e 11 a m y L., P a c e R., Spectrochim. Acta, 22, 525 (1966).

11. A bello L., P a nn et ie r G., Bull. Soc. chim. France, 10, 3776 (1967). 


\section{A. AARNA, L. MOLDER, AIME SUURPERE}

\section{FENOOLIDE ASSOTSIATSIOON MITTEPOLAARSETES LAHUSTITES. II}

Ebulliostaatilisel meetodil saadud katseandmete alusel määrati hüdroksübenseeni, 2-metüül-, 3-metüül- ja 4-metüülfenooli assotsiatsioonikonstandid $n$-heksaanis, tsükloheksaanis ja $n$-heptaanis kahel temperatuuril. Neis tingimustes kulgeb fenoolide assotsiatsioon ahelreaktsiooni skeemi järgi, kusjuures monomeer liitub eelistatult kōrgemale assotsiaadile. Fenoolide suhteline kalduvus assotsieerumisele sureneb reas 2-metüülfenool $<$ $<$ hüdroksübenseen $<3$-metüülfenool $<4$-metüülfenool.

Assotsiatsioonikonstantide temperatuurilisest olenevusest arvutati vesiniksideme entalpia $(-\Delta \mathrm{H})$ monomeeri liitumisel erineva pikkusega ahelale. Lahusti segava mõju puudumise tōttu on $-\Delta \mathrm{H}$ väärtused süsivesinikkudes toimuva dimerisatsiooni puhul mōnevōrra suuremad kui tetraklorometaanis ja benseenis toimuva puhul. Monomeeri liitumisel ūle kolme fenoolimolekuli sisaldavale ahelale on $-\Delta \mathrm{H}$ antud fenooli puhul konstantne.

\section{A. AARNA, L. MOLLDER, AIME SUURPERE}

\section{ASSOCIATION OF MONOFUNCTIONAL PHENOLS IN NON-POLAR SOLVENTS. II}

Self-association constants calculated from ebullioscopic data for phenol, $o-, m$ - and pcresol in $n$-hexane, cyclohexane and $n$-heptane solution at two temperatures are presented. In these systems continuous association of phenols occurs with polymers of all orders. while formation of higher polymers is favoured. The tendency of phenols to associate increases in the order $o$-cresol $<$ phenol $<m$-cresol $<p$-cresol.

The hydrogen bond enthalpy $(-\Delta \mathrm{H})$ for joining a monomer to chain molecules of different size has been calculated from the temperature dependence of association constants. The enthalpy of dimer formation is somewhat higher in hydrocarbons than in benzene and $\mathrm{CCl}_{4}$ solutions. When a monomer joins a polymer containing more than three phenol molecules, the values of $-\Delta \mathrm{H}$ for given phenol become constant. 